\title{
Research and Practice on the Teaching System Being Centered on Normal College Students Teaching Skills Training in the Background of Universities Transition
}

\author{
Yuhua Su ${ }^{1, a}$, Wei Jiang ${ }^{2, b, ~}{ }^{*}$ and Shi Wei ${ }^{1, c}$ \\ ${ }^{1}$ School of Science, Hezhou University, Hezhou, Guangxi, 542899, China \\ ${ }^{2}$ Department of Personnel, Hezhou University, Hezhou, Guangxi, 542899, China \\ a107913494@qq.com, b122484412@qq.com, '260870681@qq.com
}

Keywords: Universities Transition, Normal College Students, Teaching Skills, Teaching System

\begin{abstract}
With the continuous development of China's economy, the society needs a large number of high-level skilled personnel, while the majority of normal college graduates currently unable to meet the market or industry requirements for highly skilled personnel. To achieve the "demographic dividend" to" talent dividend "conversion, training objectives and training model is bound to change. There are some problems in normal college students' teaching skills training in most of our colleges and universities. The article points out skills training should be an integral training with theory penetration, and points out that it needs to reform from the training concept, training content system, improve the regulatory frame work and provide opportunities to practice and other aspects.
\end{abstract}

\section{Introduction}

For a long time, the presence of heavy research and higher education, the teaching of the ills of light; in personnel training, ignoring the needs of the market, closed to engage in teaching; in the whole school building, the blind pursuit of "tall", which led to the scale of the Higher School to the greater of college graduates rose year after year, while the employment problem also become progressively more severe. At the same time, industry, business and other employers are caught in a "talent short age" embarrassment.

Since June 2013, in order to set up and the first production of teaching University of Applied Sciences(College) organized by the Union of fusion development strategy in international forums as a symbol, restructuring and development of local undergraduate institutions of higher education is rapidly becoming a major reform of the whole society. According to the deployment and Planning Ministry of Education in 1999 after more than 600 new local undergraduate colleges and universities will be gradually transformed into University of Applied Sciences(College), and tries to develop modern vocational education. This will be our higher education following the 1952 adjustment, major reforms of the last century involved the overall development of higher education after the merger of universities andlargeenrollment1990s, will center and the center of gravity of our higher education an important shift occurs.

In 2011, the "National Teacher Education Curriculum Standard(Trial)" (hereinafter referred to as the "standard") was formally promulgated by the Ministry of Education made clear that pre-service teachers training new primary and secondary schools should have some educational capacity; "on vigorously promote teacher education curriculum opinions reform "also stressed that" strengthening Teachers Education teaching ability training "" Strengthening Vocational Normal School Students basic skill straining. [1]"

\section{The Meaning and Content of Teaching Skills}

Teaching skills are the main skills of teachers. Teaching skills not only refers to the process of teaching teachers in the classroom itself, but also includes a series of job-related classroom instruction and appropriate educational values, such as: the secondary development of teaching materials, instructional design, teaching wit, jobs stay grant, after-school tutoring, teaching methods 
of use, and so on. In short, all that refers to the unique teaching ability of teachers according to certain philosophy of education, in teaching practice formation.

\section{TheMain Problem of Normal College Students' ${ }^{6}$ Teaching Skills Training in the Background of Universities Transition}

The Training Content is Monotonous and Lack of Systematic. Teachers' teaching skills is the most important structure of skills. Division in the Ministry of Education Teachers' teacher professional theory and practice "explained": teaching skills are considered teachers to use certain expertise or experience to complete the task of teaching activities some way. "Include instructional design, classroom teaching, jobs marking and after-school tutoring, teaching evaluation, teaching and research in five areas, including classroom teaching skills is the core teaching skills. Many Teachers College currently only concerned about conventional teaching skills training, such as the traditional "three pen a word," or "the words of one, then a courseware", while ignoring the teaching process design skills before the development of skills, the teaching process management skills , communication skills, organizational skills and coaching skills after the teaching process, Thinking skills, evaluation skills training. Teaching activities is extremely complex and creative activity, teaching skills often are embodied in the form of an integrated individual who has a distinct complex, holistic. The current fragmented, incomplete skills training system so that the content of Students' Teaching Skills blunt, even to expand the normal teaching activities [2].

Training Means is Instrumental and Lack of Ideas and Emotional Penetration. Teaching skills to master shall be subject to certain ideas or emotions dominate. If the lack of career aspirations and career emotional penetration, it will restrict the development of normal students or potential competition to some extent. Now training tools or means are more advanced, such as using the Internet, using the micro-grid and so on. But in the increasingly sophisticated means of skills training today, normal students do not have the skills and grow, but in a way there is a lot to be desired. This phenomenon is normal students lack the concept of teaching skills training and emotional penetration related. Some trainers often train students to teach and how to teach what should be, but rarely do so and why should cherish what career to deal with the emotional skills. Passing specific methods and skills focused on classroom teaching, while ignoring the root cause of the guidance of the theory of teaching skills, which can easily lead to master the skills of students in "the trees but not the forest." This boring tool of the training may not really make normal students entry to the teaching profession had psychological conflict or numbness, fear of hardship, which to some extent become impediments in their teaching wisdom generated psychology.

Skills Organization Forms are Commonly Large Class, Lack of Practice, Personalized Guidance. Large class teaching is the main form of organization of Higher Education Teaching today, and many teaching skills may be due to fewer teachers, and students to space constraints and other factors also uses large class organization, which seriously affected the quality of teaching skills training. Skills training needs of students practice operation, only the person's high school students to experience the practical operation of its flexibility and artistry to form some of the basic skills. In addition, the current training based on only to meet the basic teaching skills of all normal college students, while ignoring some of the normal students on personal interests and hobbies of the training needs with personalized content. Due to the different needs of each individual of the same individual or different Language field environment, at different times, teaching skills to be flexible to adjust. This generates a random adjustment of wisdom for college normalstudents need to personalize education and counseling.

The lack of appropriate training of trainers, fragmented, difficult to form a joint force. The Ministry of Education explicitly requires the appointment of school teachers undertake educational curriculum teaching task, said". Accounted Education Course number less than $20 \%$ of teachers and school teachers form joint guidance of University Teachers Students mechanism to implement the dual mentoring" thus, the students' Teaching skills Training of teachers should be two parts to guide the training of teachers group that is part-time Teachers College and School instructor groups. Due to various reasons, the internal Teachers College instructor intellectual capacity and Students 
'Teaching Skills Training requirements are not balanced, you need the guidance of teachers and school Students' Teaching Skills Training unbalanced contradictions. Lack of teachers between the two groups within and close coordination, fragmented, and integration is not conducive to the coordinated development of students' teaching skills [3].

\section{Research and Practice on the Teaching System Being Centered on Normal College StudentsTeaching Skills Training in the Background of Universities Transition}

Establish a Sustainable Human Development Values for the Purpose of Skills Training. "Sustainable development of the so-called people, their essence means thorough persistence length of individual life development, balanced breadth, the depth of it." It contains a person's continuous development and improvement, also includes a comprehensive development of man. To achieve sustainable development of human beings for the purpose of skills training values, a goal to be in terms of skills training in order to improve and perfect the teachers' professional quality structure for the purpose, not just to mere skills training targeted skills training should permeate ideological, humanities, focus on cultivating social responsibility, innovative spirit and practical ability of teachers and students, and establish normal growing season from teaching, from teaching for life beliefs. Second, we must change the training body past normal students completely passive state. As a trainee college student, it is positive, and initiative of individuals. During training, students can make the content of self-selection, self-reflection. Thus, in terms of skills training, the trainer should fully mobilize the enthusiasm of the trainees, focusing on mutual exchanges, cooperation, dialogue and interaction. Third, we must change the way conventional method of indoctrination in the training methods, leaving students to practice and time for reflection, so that the training process into the inquiry process, the process of reflection. In training the trainees to consider the different interests and hobbies, targeted, individualized, personalized skills training.

Building a Comprehensive Skills Training System. Student Teachers in basic vocational skills training mainly to "Higher Normal School Students' Professional Skills Training Outline" as the basis, under the Student Teachers in vocational skills training including Mandarin and oral expression, writing standard Chinese characters and writing, teaching, teacher skills into four parts. In addition to skills in five areas of vocational skills training program to the provisions of the "standard" also provides for the following teaching skills: curriculum resource development and use of skills, understanding students' skills, communication, cooperation and communication skills, modern information technology and curriculum integration skills, classroom assessment skills, psychological diagnosis and counseling skills, teaching reflection skills, education and research skills. By internal cognitive skills training to external behavior by the knowledge representation system and the teaching of two parts of the operating system currently, there are some Normal University and Teachers College have to build more systematic training system to improve teacher skills, building shape training the complete system of teaching skills [4].

Improve Relevant Rules and Regulations. Good operating mechanism is teaching skills training to achieve good results in normal universities guarantee. First, the establishment of normal students vocational skills training relevant organizations. At present, some universities have established a corresponding normal students skills training organizations. Secondly, the relevant rules and regulations are promulgated by teaching skills. For example, some colleges and universities to develop the basic requirements for normal school Teachers skills training or implementation rules, developed a normal student skills assessment methods and mentors performance assessment methods and so on. Again, the establishment of normal college double tutorial system and part-time trainer of common guiding both inside and outside This need to develop teachers 'professional development schools, colleges and universities to attract the best teachers in primary and secondary schools were teaching each other, the formation of joint promotion Students' Teaching Skills. Finally, skills training is a long process, with the individual, therefore, relevant training system should reflect openness, selectivity or autonomy, to normal students to provide a broad space for development [5].

Provide Practice Sites and Opportunities. Students 'Teaching skills acquisition and upgrading 
teaching practice is inseparable from the real situation, the real teaching situation to help stimulate students' curiosity, to verify the effectiveness of skills training to further improve and enhance the quality of skills. "Standard" clearly states that normal students to "practice participatory educational experience and experience", pre-service teacher education institutions should "strengthen education trainee, to provide more opportunities to watch the teacher lectures," no less than one semester internship. Therefore, normal colleges should strengthen links with local primary and secondary schools, the establishment of practice base, practice teaching or replacement training system, providing ample opportunity to practice for the college students, to reflect, to learn study learn in practice, thus speeding up the pace of development of teachers' professional development .

\section{Conclusions}

The country's economic restructuring and development, industrial structural upgrading, new scientific and technological revolution triggered by information technology, applied technology are urgently needed talent. In this context, normal college student needs to increase teaching skills training, put efforts to improve the teaching skills to become an inevitable trend. Teaching skills of teachers are skilled, flexible practical skills trained in educational practice. It is the basic teaching skill normal students must have in the future as a teacher, the level of normal students directly determine the extent of the future in the professional development of teachers, but also determines the level of quality of basic education teachers. In the current context of the transformation of University of normal students teaching skills is a necessary requirement of teacher professional development. Under the severe employment pressure situation and popularization of higher education, improving the teaching skills of normal students has been more important and urgent.

\section{Acknowledgement}

This work is supported by the Project of Guangxi Education Department Key Laboratory of Symbolic Computation and Engineering Data Processing, and the Twelfth Five Year Plan education planning of Guangxi (The research and practice of the teaching system of four dimensional integrated teaching with the core of the teaching skills training in the Normal University Under the background of reform local colleges and Universities, No. 2015C421)

\section{References}

[1] Li Xu. Chinese University Teaching, Vol.11 (2012) No29, p75-77.

[2] Sunxian Bin, Fu Xianlan. Anhui University, Vol. 4 (2010) No 13, p. 61-63.

[3] Fu Liping. Chinese University Teaching, Vol. 3 (2013) No 22, p. 33-35.

[4] Wu Bin. Heilongjiang Higher Education Research, Vol. 10 (2013)No 10,p. 164-166.

[5] Wang Qun. Modern Education Science, Vol. 6 (2013) No 13, p. 41-43. 